Keywords: Helicobacter pylori; eradication; metachronous gastric cancer; prevention; randomised controlled trial; molecular alterations

\title{
Effects of Helicobacter pylori eradication on the development of metachronous gastric cancer after endoscopic treatment: analysis of molecular alterations by a randomised controlled trial
}

Maki Kawanaka ${ }^{1}$, Jiro Watari ${ }^{\star},{ }^{1}$, Noriko Kamiya ${ }^{1}$, Takahisa Yamasaki ${ }^{1}$, Takashi Kondo ${ }^{1}$, Fumihiko Toyoshima ${ }^{1}$, Hisatomo Ikehara ${ }^{1}$, Toshihiko Tomita ${ }^{1}$, Tadayuki Oshima ${ }^{1}$, Hirokazu Fukui ${ }^{1}$, Takashi Daimon ${ }^{2}$, Kiron M Das ${ }^{3}$ and Hiroto Miwa ${ }^{1}$

${ }^{1}$ Division of Gastroenterology, Department of Internal Medicine, Hyogo College of Medicine, 1-1 Mukogawa-cho, Nishinomiya, Hyogo 663-8501, Japan; ${ }^{2}$ Department of Biostatistics, Hyogo College of Medicine, Nishinomiya, Japan and ${ }^{3}$ Division of Gastroenterology and Hepatology, Departments of Medicine and Pathology, Rutgers Robert Wood Johnson Medical School, 125 Paterson Street, MEB 478B, New Brunswick, NJ 08901, USA

Background: Whether Helicobacter pylori eradication actually suppresses the development of metachronous gastric cancer (MGC) after endoscopic resection (ER) remains controversial. The aims of this study were to clarify (1) the molecular markers related to carcinogenesis in intestinal metaplasia (IM) by a cross-sectional study, and (2) the changes of those markers by an openlabel, randomised controlled trial (RCT) of $H$. pylori treatment.

Methods: First, we evaluated microsatellite instability (MSI), the methylation status at $h M L H 1, C D K N 2 A$ and APC genes, and immunoreactivity using the monoclonal antibody (mAb) Das-1 in IM in the background mucosa of 131 patients who underwent ER for gastric neoplasia and 22 chronic gastritis cases (control). Next, we performed an RCT to evaluate the changes of MSI between the H. pylori-eradicated $(n=19)$ and non-eradicated patients $(n=17)$ at 1 year among the H. pyloripositive patients.

Results: Microsatellite instability and mAb Das-1 reactivity showed significantly higher incidences in both the $H$. pylori-positive and -negative patients compared with the control group, thus suggesting that MSI and mAb Das-1 reactivity are associated with gastric neoplasia (OR=5.06 for MSI; OR=2.51 for mAb Das-1 reactivity). The RCT showed that $\mathrm{H}$. pylori eradication did not provide significant reversals of any molecular alterations including MSI (the primary end point) and other methylation statuses and mAb Das-1 reactivity (secondary end points).

Conclusions: H. pylori eradication did not produce significant changes in the molecular alterations related to carcinogenesis, suggesting that $H$. pylori treatment may not prevent the development of MGC in background mucosa with IM.

*Correspondence: Professor J Watari; E-mail: watarij@hyo-med.ac.jp

Revised 19 September 2015; accepted 4 November 2015; published online 15 December 2015

(c) 2016 Cancer Research UK. All rights reserved 0007-0920/16 
Gastric cancer remains the second most common cause of cancer deaths in the world (Ferlay et al, 2010). Helicobacter pylori (H. pylori) infection is considered a main risk factor for the development of gastric cancer, especially the intestinal type (Correa et al, 1990; Sipponen and Hyvärinen, 1993; International Agency for Research on Cancer, 1994; Uemura et al, 2001). It has been postulated that $H$. pylori infection causes chronic gastritis, gastric atrophy (usually with gastric intestinal metaplasia (IM)), dysplasia, and gastric cancer (Correa, 1988). In this process, IM is believed to be a precancerous condition of the stomach (Correa, 1988; Filipe et al, 1994; Dinis-Ribeiro et al, 2012).

The roles of a number of genetic and epigenetic alterationsincluding microsatellite instability (MSI) and the promoter hypermethylation of multiple tumour-related genes-have been reported to be involved in gastric cancer and precancerous conditions of the stomach (Toyota et al, 1999; To et al, 2002; Chan et al, 2003, 2006; Kang et al, 2003, 2008, Tanaka et al, 2006; Maekita et al, 2006; Leung et al, 2006; Perri et al, 2007; Zaky et al, 2008; Park et al, 2009; Dong et al, 2009; Tahara et al, 2010; Sepulveda et al, 2010; Li et al, 2011; Watari et al, 2012; Shin et al, 2013). We also observed that the IM of a colonic phenotype, detected by the monoclonal antibody (mAb) Das-1 (formerly known as $7 \mathrm{E}_{12} \mathrm{H}_{12}, \operatorname{IgM}$ isotype) (Das et al, 1987), is strongly associated with gastric cancer (Mirza et al, 2003; Watari et al, 2008, 2012).

A 2009 meta-analysis showed that $H$. pylori eradication seems to reduce the risk of the development of gastric cancer (Fuccio et al, 2009). However, a later study from Japan showed that even after an $H$. pylori infection is cured and gastric inflammation is eliminated, the risk of the development of gastric cancer remains, and the risk increases in the background of gastric mucosal atrophy (Take et al, 2011). This finding provoked many arguments on whether H. pylori eradication would actually prevent the occurrence of gastric cancer in patients with a precancerous condition.

With respect to the effects of $H$. pylori eradication on the prevention of metachronous gastric cancer (MGC) after endoscopic resection (ER), studies based in Japan and Korea indicated that $H$. pylori treatment reduced the risk of the development of new gastric cancer in patients who underwent ER (Uemura et al, 1997; Fukase et al, 2008; Bae et al, 2014; Jung et al, 2015). A similar conclusion was reached in a 2014 metaanalysis (Yoon et al, 2014). However, three recent retrospective studies (Maehata et al, 2012; Kato et al, 2013; Jung et al, 2015) and a prospective open-label trial (Choi et al, 2014) showed that H. pylori eradication did not reduce the incidence of MGC in patients who underwent ER.

Gastric cancer also occurred to some degree in $H$. pylorinegative patients who had been treated with either anti-H. pylori therapy or by natural eradication (Fukase et al, 2008; Maehata et al, 2012; Kato et al, 2013; Choi et al, 2014; Bae et al, 2014; Yoon et al, 2014; Jung et al, 2015), and thus the findings of other studies (Maehata et al, 2012; Kato et al, 2013; Jung et al, 2015) similarly raise the question of whether $H$. pylori eradication actually suppresses the development of MGC.

We reported that $H$. pylori eradication reduced the MSI and $\mathrm{mAb}$ Das-1 reactivity in IM (Tanaka et al, 2006; Watari et al, 2008), and a case-control study showed that patients in whom these biomarkers persist after eradication might have a high risk of developing MGC (Watari et al, 2012). Several reports showed that $H$. pylori eradication can significantly reduce gene methylation in chronic gastritis mucosa, thus delaying or reversing $H$. pyloriinduced gastric carcinogenesis (Leung et al, 2006; Chan et al, 2006; Perri et al, 2007; Nakajima et al, 2010). However, the changes in the molecular phenotype in the background mucosa following H. pylori treatment in patients who have undergone ER for gastric neoplasms remain unclear (Maekita et al, 2006; Watari et al, 2012; Shin et al, 2013).
In the present study, (1) we analysed the differences of molecular markers related to carcinogenesis in IM as a precancerous condition, in the background mucosa of gastric cancer patients with/without H. pylori infection (Study 1). (2) We also followed patients who received or did not receive $H$. pylori treatment after ER for gastric neoplasia (including noninvasive low- or high-grade neoplasia and intramucosal carcinoma) for 1 year in an open-label, randomised controlled trial (RCT), and then we examined whether H. pylori eradication changed the risk markers clarified in Study 1 (Study 2).

\section{MATERIALS AND METHODS}

\section{Study 1}

Patients and sample size. Between August 2010 and December 2013, 251 consecutive patients with a total of 298 neoplasias comprised of gastric adenomas $(n=29)$ and gastric cancers $(n=269)$ were treated with endoscopic submucosal resection (ESD) at Hyogo College of Medicine Hospital. The patients were 180 men $(71.1 \%)$ and 71 women $(28.3 \%)$, and their mean age was $71.2 \pm 9.7$ years (range 23-89 years). All of the patients were Japanese. We used the criteria of the Japanese Research Society for Gastric Cancer (Japanese Gastric Cancer Association, 2011) as the histological criteria of gastric cancer and adenoma in this study. These lesions may correspond to noninvasive low- or high-grade neoplasia (Categories 3 and 4) or intramucosal carcinoma in invasive neoplasia (Category 5) based on the revised Vienna classification (Schlemper et al, 2000), and thus these lesions were grouped together as the study's gastric cancer group (Group GC) because they represent a common end point for endoscopic therapeutic intervention.

As Study 1, we performed a cross-sectional study to clarify the differences in the molecular abnormalities in IM between gastric cancer patients and chronic gastritis patients (controls). The outcome measure that we used for the 251 patients were as follows: the prevalence of molecular alterations such as genetic and epigenetic alterations including MSI, the methylation of $\mathrm{CpG}$ islands at various genes, and $\mathrm{mAb}$ Das- 1 reactivity related to gastric carcinogenesis between the $H$. pylori-positive and -negative cases. We excluded the cases of the $H$. pylori-negative patients in whom the $H$. pylori was eradicated within 1 year, because these patients were likely to have had gastric cancer at the time of H. pylori treatment. Patients with a history of oesophagectomy or gastrectomy were also excluded.

Microsatellite instability and other molecular markers were analysed in 131 of the 251 patients who underwent ESD. Additionally, the same molecular alterations were available in 22 H. pylori-positive chronic gastritis patients with IM (controls) who underwent endoscopy for a medical check-up during the same period. When the incidence of MSI is assumed to be $37.1 \%$ in Group GC and $13.6 \%$ in the control group, the above sample size can achieve a power of $\sim 60 \%$ to detect a difference at the level significance of $\alpha=0.05$ (two-sided $\chi^{2}$ test). This presumption was based on the incidence of MSI, which was 37.1\% (69 of 186) in Group GC and 13.6\% (14 of 103) in the control group from our previous studies of the same patient series (Tanaka et al, 2006; Zaky et al, 2008; Watari et al, 2012). The molecular alterations in 131 patients with 131 neoplasias including 119 early gastric cancers from Group GC were compared with those in the controls. Written informed consent was obtained from all patients before the start of the study, and the study design was approved by the Ethics Committee of Hyogo College of Medicine.

H. pylori status and DNA extraction. During each patient's endoscopy, three biopsy specimens were taken from the greater 
curvatures of the antrum and the corpus and the lesser curvatures of the angulus (one from each site). Each biopsy specimen was used for histologic examination by haematoxylin-eosin (H\&E) stain, $H$. pylori status by Giemsa stain and mAb Das- 1 stain, and DNA extraction. The $H$. pylori status was analysed in each patient by two methods: Giemsa staining and serum H. pylori-IgG antibody with an ELISA (enzyme-linked immunosorbent assay) Kit using the E plate test (Eiken Kagaku, Tokyo). A patient was regarded as positive for $H$. pylori if the result of at least one of these two methods was positive.

From paraffin-embedded blocks of the biopsy specimens, 7- $\mu \mathrm{m}$ tissue sections were cut for DNA extraction. DNA was extracted only from goblet IM (incomplete type) using the QIAamp DNA Micro Kit (Qiagen, Hilden, Germany). Goblet IM was isolated via a laser capture microdissection (LCM) system, the PALM MicroBeam (Microlaser Technologies, Munich, Germany), to avoid DNA contamination of inflammatory or stromal cell nuclei based on the methodology described (Tanaka et al, 2006; Zaky et al, 2008; Watari et al, 2012) (Supplementary Figure S1).

Evaluation of MSI by high-resolution fluorescent microsatellite analysis. As reported (Tanaka et al, 2006; Zaky et al, 2008; Watari et al, 2012), we examined five microsatellite loci on chromosomes for MSI based on the revised Bethesda panel (Umar et al, 2004) as follows: 2p (BAT26), 4q (BAT25), 2p (D2S123), 5q (D5S346) and $17 \mathrm{p}$ (D17S250). The polymerase chain reaction (PCR) products were evaluated for MSI by capillary electrophoresis using an ABI PRISM 310 Genetic analyser (Applied Biosystems, Foster City, CA, USA) and automatic sizing of the alleles using a GeneMapper (Applied Biosystems). The MSI status was judged according to previous reports (Supplementary Figure S2) (Tanaka et al, 2006; Zaky et al, 2008; Watari et al, 2012).

Sodium bisulphite modification of DNA. The DNA was subjected to sodium bisulphite modification. In brief, purified DNA samples were chemically modified by sodium bisulphite with the EpiTect Plus DNA Bisulphite Kit (Qiagen) to convert all unmethylated cytosines to uracils while leaving the methlcytosines unaltered. The bisulphite-modified DNA was amplified using primer pairs that specifically amplify either the methylated or unmethylated sequences of the three tumour-related genes, $h M L H 1, C D K N 2 A$, and APC (adenomatous polyposis coli).

Methylation-sensitive high-resolution melting analysis. We performed a methylation-sensitive high-resolution melting (MSHRM) analysis as described (Balic et al, 2009). Briefly, the PCR amplification and MS-HRM analysis were performed using a LightCycler 480 Real-Time PCR System (Roche, Mannheim, Germany). Each PCR reaction mix in a $20-\mu$ l total volume contained $10 \mu \mathrm{l} 1 \times$ LightCycler 480 High-Resolution Melting Master mix (Roche Diagnostics, Penzberg, Germany), $1 \mu \mathrm{l}$ of $10 \mathrm{pmol} \mu \mathrm{l}^{-1}$ of each primer for $h M L H 1, C D K N 2 A$ or APC (each; forward and reverse primer; Life Technologies Japan, Tokyo), $0.6 \mu \mathrm{l}$ nuclease-free water, and $5 \mu \mathrm{l}$ bisulphite-treated DNA template (5-10 $\mathrm{ng} \mu \mathrm{l}^{-1}$ ), with $3 \mathrm{mmoll}^{-1}$ final $\mathrm{MgCl}_{2}$ for each of the three genes.

The primer sequences of all genes for the methylated and unmethylated forms, PCR, and MS-HRM conditions are summarised in Supplementary Tables 1 and 2. All tests were performed in duplicate. Methylated and unmethylated DNA sets (EpiTect PCR Control DNA Set; Qiagen) were used as 100\% methylated and $0 \%$ unmethylated controls. Methylation standards (10\% and 50\%) made by diluting the fully methylated control in the unmethylated DNA were used as controls. The percentages of methylation of $0 \%$, $10 \%, 50 \%$ and $100 \%$ were used to draw the standard curve (Supplementary Figure S3).
Methylation was scored as low $(<10 \%)$, moderate $(\geqslant 10 \%$ to $<50 \%)$, and high-level $(\geqslant 50 \%)$ methylation. When low-level methylation is detected, the biological significance is still not established (Balic et al, 2009). Although there are a few reported cutoffs for the scoring criteria of gene methylation using the MSHRM assay (Balic et al, 2009; Morandi et al, 2010; Avraham et al, 2012; Meng et al, 2012; Pang et al, 2014), we regarded only the samples with $>10 \%$ methylation as methylated (Meng et al, 2012; Pang et al, 2014).

Immunoperoxidase assays with $m A b$ Das-1. Serial sections were stained with the mAb Das-1 (an IgM mAb highly specific against colonic phenotype) using sensitive immunoperoxidase assays as described (Das et al, 1987; Mirza et al, 2003; Watari et al, 2008, 2012). A specimen was considered positive if both a substantial number of cells and more than one gland were reactive to this $\mathrm{mAb}$ (Supplementary Figure S4). If only occasional goblet cells were stained, then the sample was defined as negative (Das et al, 1987; Mirza et al, 2003; Watari et al, 2008, 2012).

\section{Study 2}

Patients. We performed an open-label RCT to determine whether $H$. pylori treatment changed the molecular markers in IM in $H$. pylori-positive patients who underwent ESD during the same period as that of Study 1. All patients who showed positivity for MSI in Study 1 were enrolled in this RCT. The exclusion criteria were as follows: (1) patients with malignancy in other organs; (2) patients with an allergy to drugs used for $H$. pylori eradication; (3) a past episode of $H$. pylori treatment; (4) patients regularly taking a nonsteroidal anti-inflammatory drug, including aspirin; (5) patients with a history of oesophagectomy or gastrectomy; and (6) patients who were determined by their physicians to be unqualified for any other reason. In the cases of patients who were histologically diagnosed based on the finding that the resected lesion of ESD showed submucosal invasion $(>500 \mu \mathrm{m})$ or those with positive lymphovascular invasion, surgery was recommended. A follow-up endoscopy with biopsies was performed at 1 year after intervention to assess the changes in molecular markers.

Outcome measures. The primary end point of Study 2 was the changes in MSI between the H. pylori-eradicated and noneradicated groups at 1 year among the $H$. pylori-positive patients. Secondary end points were the alterations of other molecular markers, that is, $\mathrm{CpG}$ island methylation evaluated in Study 1 and $\mathrm{mAb}$ Das-1 reactivity in IM. Study 2 was conducted at our college hospital according to the Declaration of Helsinki and adhered to good clinical practices. The study protocol was approved by the Ethics Committee of our college. Informed written consent was obtained from all participants before they entered the study. This trial is registered with the UMIN Clinical Trials Registry (number UMIN000006206).

Randomisation, therapy, and follow-up. Randomisation was performed by drawing lots from a sealed envelope that contained a preassigned random treatment: the $H$. pylori-eradicated group or the non-eradicated group. The patients in the eradicated group $(n=22)$ received lansoprazole $30 \mathrm{mg}$, amoxicillin $750 \mathrm{mg}$, and clarithromycin $200 \mathrm{mg}$ two times daily for 1 week. The patients in the non-eradicated group $(n=19)$ received standard care but no antibiotics for eradication. Whether the eradication succeeded or not was established by the administration of a ${ }^{13} \mathrm{C}$ urea breath test to each patient 6-8 weeks after the completion of the H. pylori treatment.

Participants in whom the eradication treatment failed were invited to receive the second-line therapy: lansoprazole $30 \mathrm{mg}$, 
amoxicillin $750 \mathrm{mg}$, and metronidazole $250 \mathrm{mg}$, all two times daily for 1 week. $H$. pylori status was checked by the same procedures as those used to confirm infection at baseline. Following successful treatment results, all patients were then prospectively followed up for 1 year. In both patient groups, biopsy specimens were taken from the same portions in the same manner as that used at baseline after intervention, as described in Study 1.

Sample size. Our previous case-control study (Watari et al, 2012) showed that the improved incidence of MSI in IM at 1 year after $H$. pylori treatment was $\sim 70 \%$ in the eradicated group and $15 \%$ in the non-eradicated group. Based on this result, in the present study, we therefore calculated that we needed to have $16 \mathrm{H}$. pyloripositive patients showing MSI in each group to have a power of $80 \%$ to detect a difference at the level significance of $\alpha=0.05$ (twosided). Considering a $10 \%$ patient loss to follow-up, we calculated that at least 18 patients in each group (36 in total) were required.

Statistical analysis. Continuous data are reported as means with standard deviations (s.d.'s), and categorical data are provided as frequencies with proportions. The data were assessed by Welch's $t$-test assuming unequal variances between two independent groups and by the $\chi^{2}$ test or Fisher's exact test for comparisons between two proportions in Studies 1 and 2. In Study 1, a multivariate logistic regression analysis was also performed to identify the molecular alterations associated with gastric neoplasia. All statistical tests were two-sided, and $P$-values $<0.05$ were considered significant. Statistical analyses were performed with GraphPad Prism5 (GraphPad Software, La Jolla, CA, USA) or StatView version 5.0 (SAS Institute Inc., Cary, NC, USA).

\section{RESULTS}

\section{Study 1}

Patient characteristics. The characteristics of the Study 1 patients are shown in Table 1 . Twenty-nine patients $(22.1 \%)$ were found to be negative for $H$. pylori. Of these patients, eight had undergone $H$. pylori treatment more than 1 year earlier. The remaining 21 patients were not previously treated for $H$. pylori eradication, and their infections were thus considered naturally eradicated. The endoscopic findings of all 21 patients revealed atrophic gastritis. Of these patients, severe atrophic gastritis (open type, O-II to -III) according to the Kimura and Takemoto classification (Kimura and Takemoto, 1969) was identified in 19 patients (90.5\%). This result strongly suggests a past $H$. pylori infection. There were no significant differences in age, gender, smoking, or body mass index among the $H$. pylori-positive and -negative groups and the controls.

Microsatellite instability, epigenetic alterations, and mAb Das-1 reactivity. The incidence of MSI, hypermethylation at three genes, and $\mathrm{mAb}$ Das-1 reactivity to IM did not show significant differences among all neoplasia cases (Group GC), regardless of the presence or absence of $H$. pylori infection (Table 2). In contrast, MSI showed significantly higher incidences in the Group GC, including $H$. pylori-positive and -negative cases compared with those in the non-neoplasia (control) group $(P=0.008$ and $P=0.02$, respectively). Monoclonal antibody Das-1 reactivity against IM was also frequently observed in the Group GC patients whether they were positive or negative for $H$. pylori infection compared with the controls $(P=0.07$, both). In the multivariate logistic regression analysis, these two markers were significantly

Table 1. Characteristics of the patients examined in Study 1

\begin{tabular}{|c|c|c|c|c|c|}
\hline & \multicolumn{2}{|c|}{ Group GC } & \multicolumn{3}{|c|}{ Control (\%) } \\
\hline & \multirow[b]{2}{*}{$\begin{array}{c}\text { H. pylori + ve (\%) } \\
(n=102)\end{array}$} & \multirow[b]{2}{*}{$\begin{array}{c}\text { H. pylori-ve (\%) } \\
(n=29)\end{array}$} & \multirow[b]{2}{*}{$(n=22)$} & \multicolumn{2}{|c|}{$P$-value } \\
\hline & & & & vs $H$. pylori + ve & vs $H$. pylori - ve \\
\hline Mean age \pm s.d. (years) & $72.8 \pm 7.5$ & $71.4 \pm 10.4$ & $68.3 \pm 12.7$ & 0.12 & 0.33 \\
\hline Male : Female & $72: 30$ & $20: 9$ & $14: 8$ & 0.52 & 0.69 \\
\hline Mean BMI \pm s.d. $\left(\mathrm{kg} \mathrm{m}^{-2}\right)$ & $22.8 \pm 3.2$ & $23.2 \pm 4.5$ & $22.2 \pm 3.0$ & 0.35 & 0.57 \\
\hline
\end{tabular}

Table 2. Comparison of molecular alterations between Group GC and the controls

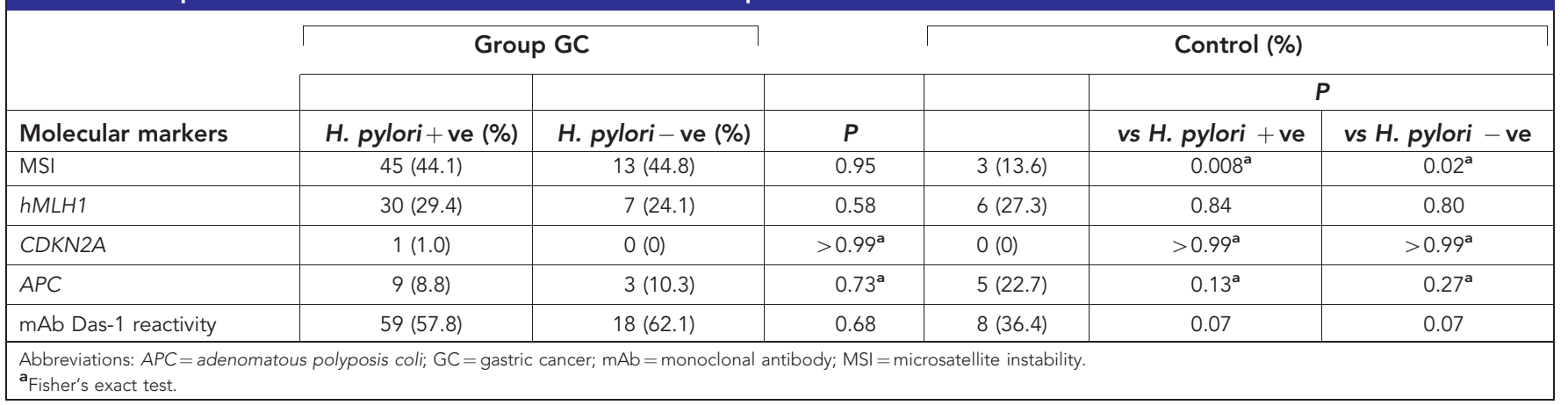




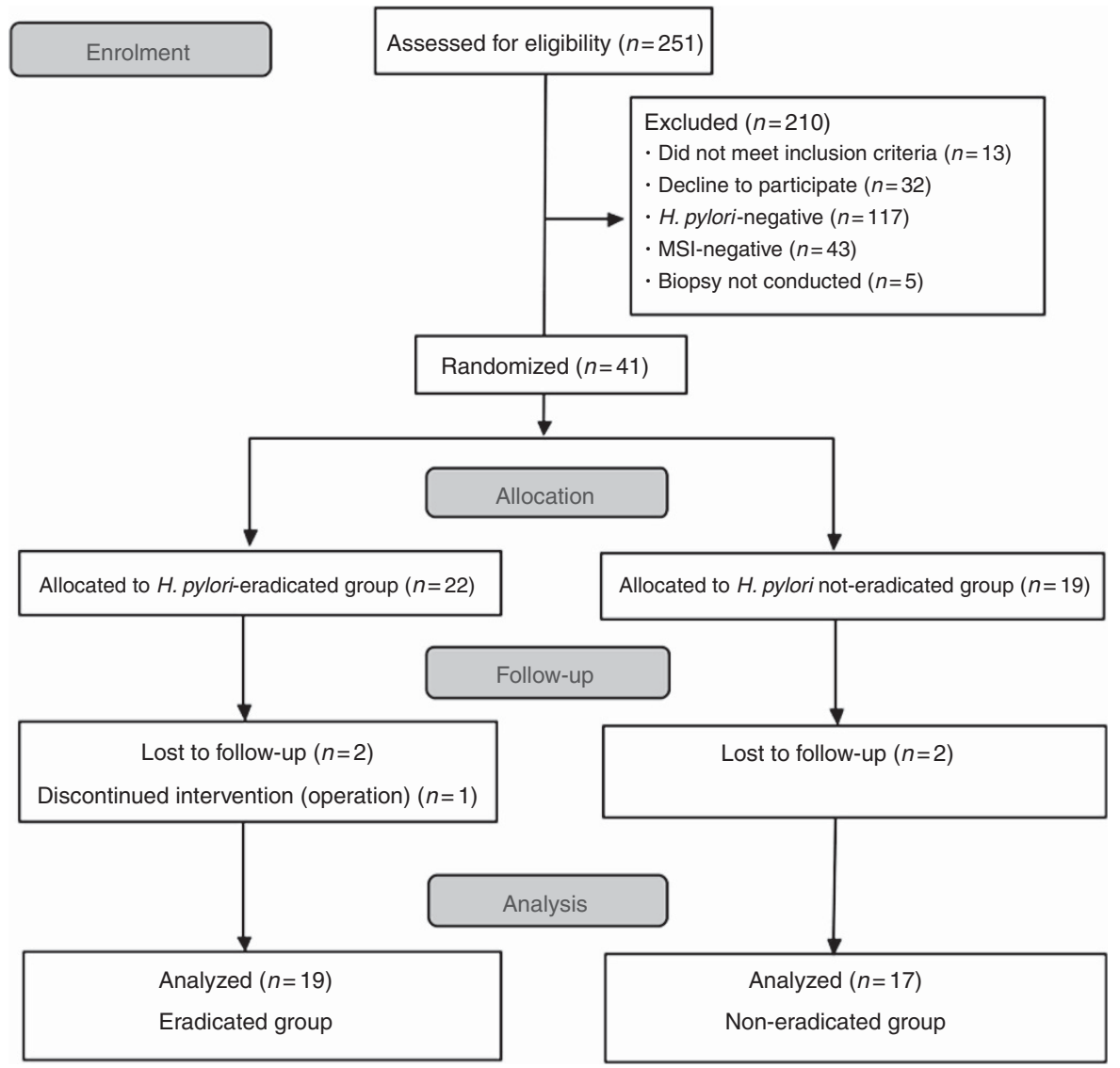

Figure 1. CONSORT flow chart for Study 2.

associated with gastric neoplasia (odds ratio $(\mathrm{OR})=5.06,95 \%$ confidence interval (CI) $1.41-18.09, P=0.01$ for MSI; OR $=2.51$, 95\% CI: $0.96-6.55, P=0.06$ for $\mathrm{mAb}$ Das- 1 reactivity).

Microsatellite instability is thought to be significantly associated with loss of $h M L H 1$ gene (Umar et al, 2004). Of the 61 MSIpositive cases in the present study, (58 in Group GC and 3 controls), only 13 patients $(21.3 \%)$ showed positivity for hypermethylation at $h M L H 1$, suggesting that deficiencies in not only $h M L H 1$ but also other mismatch repair genes may cause MSI in IM.

\section{Study 2}

Patient characteristics. From November 2010 to May 2012, a total of 251 patients who underwent ESD were screened and 210 were excluded; 41 were enrolled in Study 2. The patients who showed positivity for MSI were allocated to the eradicated $(n=22)$ and non-eradicated $(n=19)$ groups, and were followed over a 1 -year period. Two patients in the eradicated group and two patients in the non-eradicated groups dropped out during the follow-up. Out of these four patients, one patient in the non-eradicated group was transferred to another hospital for the treatment of acute renal failure. The two patients in the eradicated group and the other patient in the non-eradicated group did not return for follow-up at 1 year despite repeated calls. One patient in the eradicated group was excluded because the patient underwent surgery because of submucosal invasion. The respective dropout rates were $9.1 \%$ and $10.5 \%$ in the eradicated and non-eradicated groups, respectively, which are not significantly different. A final total of 36 patients were included in the analysis (CONSORT flow chart for Study 2; Figure 1). The baseline characteristics illustrating that there were
Table 3. Baseline characteristics of a randomised controlled trial (Study 2)

\begin{tabular}{|l|c|c|c|}
\hline & $\begin{array}{c}\text { Eradicated } \\
\text { group (\%) } \\
(\mathbf{n = 2 2 )}\end{array}$ & $\begin{array}{c}\text { Non-eradicated } \\
\text { group (\%) } \\
(\mathbf{n = 1 9 )}\end{array}$ & P-value \\
\hline Mean age \pm s.d. (years) & $72.5 \pm 7.8$ & $73.8 \pm 7.1$ & 0.69 \\
\hline Male: Female & $17: 5$ & $12: 7$ & 0.32 \\
\hline Alcohol drinking & $6(27.3)$ & $9(47.3)$ & 0.18 \\
\hline Current smoking & $3(13.6)$ & $4(21.1)$ & $0.68^{\text {a }}$ \\
\hline $\begin{array}{l}\text { Mean BMl } \pm \text { s.d. } \\
\text { (kg m }{ }^{-2} \text { ) }\end{array}$ & $23.8 \pm 2.4$ & $22.8 \pm 3.0$ & 0.44 \\
\hline $\begin{array}{l}\text { Abbreviation: BMl=body mas index. } \\
\text { a Fisher's exact test. }\end{array}$ & \\
\hline
\end{tabular}

no other significant differences between the eradicated and noneradicated groups are shown in Table 3.

Microsatellite instability changes between baseline and at 1 year after the intervention. The baseline incidence of molecular alterations in IM was balanced between the eradicated and noneradicated groups (Table 4). At 1 year after the intervention, the condition of MSI in the IM changed to stable in $73.7 \%$ (14 of 19) of the eradicated group patients and in $58.8 \%$ (10 of 17) of the noneradicated group patients, with no significant difference in the change of MSI after the intervention between the groups (Table 5).

Changes of other molecular markers between baseline and 1 year after the intervention. At baseline, the incidence of promoter methylation at $h M L H 1, C D K N 2 A$, and $A P C$ genes and the mAb Das-1 reactivity were not significantly different between the 
eradicated and non-eradicated groups (Table 4). At 1 year fter the intervention, most cases showed unchanged molecular alterations in both groups, and the incidences of improved molecular markers were also not significantly different between the eradicated and non-eradicated groups (by Fisher's exact test) (Table 5).

\section{DISCUSSION}

This is the first RCT that showed whether $H$. pylori eradication improves the molecular markers related to carcinogenesis in the background mucosa of patients who underwent ER for gastric neoplasia. Our results showed that MSI and mAb Das-1 reactivity in IM were detected significantly more frequently in the patients with neoplasias (Group GC) compared with the controls, thus suggesting that MSI and mAb Das-1 reactivity in IM are associated with gastric neoplasia as reported (Tanaka et al, 2006; Zaky et al, 2008; Watari et al, 2012). Interestingly, the incidences of MSI and $\mathrm{mAb}$ Das-1 reactivity in IM were not significantly different between the $H$. pylori-positive and -negative patients with neoplasia. These results therefore indicate that $H$. pylori eradication may not change the course of molecular alterations once gastric cancer has occurred in the stomach. Indeed, the open-label RCT in Study 2 showed that $H$. pylori eradication did not provide a significant reversal of any molecular alterations compared with no treatment for $H$. pylori infection.

Gastric cancer is frequently associated with a background of IM, which is the hallmark precancerous condition in $H$. pyloriassociated gastric carcinogenesis (Correa, 1988; Filipe et al, 1994; Dinis-Ribeiro et al, 2012). The molecular signatures identified in IM as well as in neoplasias are thus likely to represent molecular markers of $H$. pylori-associated gastric cancer pathways. Several studies, including ours, showed that MSI may have a role in early

\section{Table 4. Summary of molecular alterations at baseline} (Study 2)

\begin{tabular}{|c|c|c|c|}
\hline & $\begin{array}{l}\text { Eradicated } \\
\text { group (\%) } \\
(n=22)\end{array}$ & $\begin{array}{l}\text { Non-eradicated } \\
\text { group (\%) } \\
(n=19)\end{array}$ & $P$-value \\
\hline $\mathrm{MSI}$ & $22(100)$ & $19(100)$ & - \\
\hline hMLH1 & $5(22.7)$ & $3(15.8)$ & $0.70^{a}$ \\
\hline CDKN2A & $1(4.5)$ & $0(0)$ & $>0.99^{a}$ \\
\hline$A P C$ & $0(0)$ & $3(15.8)$ & $0.09^{a}$ \\
\hline $\begin{array}{l}\text { mAb Das-1 } \\
\text { reactivity }\end{array}$ & $15(68.2)$ & $13(68.4)$ & 0.99 \\
\hline \multicolumn{4}{|c|}{$\begin{array}{l}\text { Abbreviations: } A P C=\text { adenomatous polyposis coli; } \mathrm{mAb}=\text { monoclonal antibody; } \mathrm{MSI}= \\
\text { microsatellite instability. } \\
\text { a Fisher's exact test. }\end{array}$} \\
\hline
\end{tabular}

events leading to gastric carcinogenesis (Chung et al, 1996; Buonsanti et al, 1997; Gologan et al, 2005; Tanaka et al, 2006; Zaky et al, 2008; Sugai et al, 2010; Watari et al, 2012). The results of the present study indicated that MSI could be a risk marker for identifying 'high-risk' IM related to gastric carcinogenesis.

In addition, the patients' MSI status did not show a significant alteration following the eradication as the primary end point in our RCT. According to two RCTs from Japan and Korea, the effects of $H$. pylori eradication on the prevention of MGC after ER are still controversial (Fukase et al, 2008; Choi et al, 2014). Although a recent meta-analysis showed that eradication reduced the occurrence of MGC $(\mathrm{OR}=0.42,95 \% \mathrm{CI}$ : 0.32-0.56) (Yoon et al, 2014), a study that followed-up many patients $(n=1258)$ for a long time (up to 5 years) (Kato et al, 2013) was not included in the metaanalysis. Taking into account other relevant studies (Maehata et al, 2012; Kato et al, 2013; Jung et al, 2015) and our molecular study and RCT, it remains possible that $H$. pylori eradication may not be effective for the prevention of the development of MGC.

In contrast to our results, Fuccio et al (2009) stated that based on their meta-analysis, $H$. pylori treatment seems to reduce the risk of gastric cancer. However, the patients in their meta-analysis were heterogeneous populations consisting of chronic gastritis, dysplasia, and early cancer. The difference in study populations may be the reason for the differing results between our findings and the conclusion by Fuccio et al (2009). It is evident that gastric cancer still occurs to some degree after the ER of gastric cancer and successful eradication of $H$. pylori (Wong et al, 2004; Fukase et al, 2008), and multiple gastric cancers are commonly observed in $>10 \%$ of patients with gastric cancer (Marrano et al, 1987). Namely, the background mucosa once gastric cancer has developed may have a high risk for MGC development compared with chronic gastritis mucosa without neoplasia. Indeed, in the present study the incidence of MSI and mAb Das-1 reactivity was significantly higher in the patients with gastric cancer (Group GC) compared in those without (chronic gastritis patients as controls).

Helicobacter pylori infection has been shown to contribute to the hypermethylation of various genes involved in gastric carcinogenesis (Toyota et al, 1999; To et al, 2002; Chan et al, 2003, 2006; Kang et al, 2003, 2008; Leung et al, 2006; Maekita et al, 2006; Perri et al, 2007; Dong et al, 2009; Park et al, 2009; Sepulveda et al, 2010; Tahara et al, 2010; Li et al, 2011). It was reported that the DNA methylation of the promoter region of several genes (Chan et al, 2006; Leung et al, 2006; Perri et al, 2007; Sepulveda et al, 2010) was reversed after $H$. pylori eradication therapy in chronic gastritis patients. Generally, CpG island hypermethylation can be induced by chronic inflammation (Chan et al, 2006; Perri et al, 2007), and methylation profiles obtained from noncancerous gastric mucosae could be affected by the activity of gastritis. The methylation levels observed during a currently active $H$. pylori infection may thus not

Table 5. Changes in molecular markers revealed by the randomised controlled trial (Study 2)

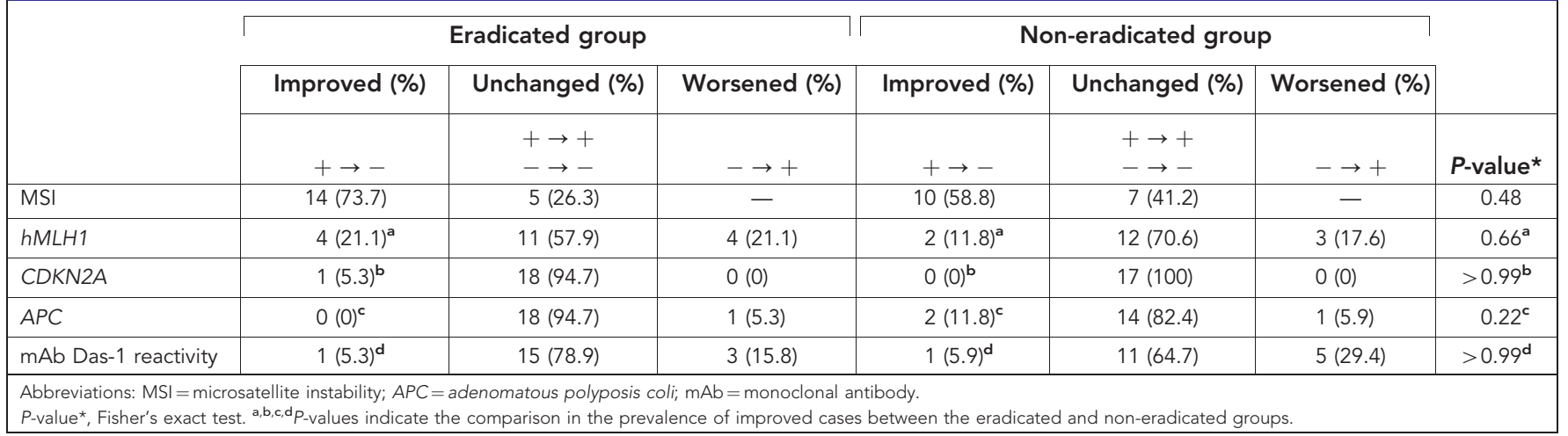


necessarily reflect the future risk of developing gastric cancer (Nakajima et al, 2010). All of the previous studies of methylation were conducted using DNA extracted from the whole biopsy tissues, and thus their results were affected by the contamination of inflammatory cells. Namely, the elimination of inflammatory cells by $H$. pylori treatment may affect the reverse of methylation in cases in which whole biopsy samples are used. In our present study, therefore, we used LCM to avoid the DNA contamination of inflammatory or stromal cell nuclei.

Previous studies of the molecular changes induced by $H$. pylori eradication were focused exclusively on chronic gastritis mucosa without gastric neoplasia (non-neoplastic mucosa), although a few studies reported the effects of eradication on CpG methylation in the background mucosa with gastric cancer (Nakajima et al, 2010; Shin et al, 2013). In addition, epigenetic alterations were evaluated mostly by methylation-specific PCR (MSP). Although MSP has high analytical sensitivity and is the most widely used method for the analysis of DNA methylation, the method has some limitations; it gives many false-positive results and is qualitative (Kristensen and Hansen, 2009). The MS-HRM analysis used in our study is applicable for the very sensitive and semiquantitative assessment of methylation levels in an unmethylated background (Wojdacz and Dobrovic, 2007).

Shin et al (2013) investigated the changes in the DNA methylation after eradication in the background mucosa with cancer, as in the present study. Their results are similar to ours: a decrease in the MOS methylation level was not observed among patients with IM or those with neoplasias including gastric cancer, and the methylation level in MOS was persistently increased in the patients with gastric cancer $(P<0.01)$ even after $H$. pylori eradication (Shin et al, 2013). In contrast, Nakajima et al (2010) showed that the FLNc and THBD methylation levels quantified by real-time MSP were significantly decreased at 1 year in patients who had undergone ER, and this result was correlated with the degree of inflammatory cell infiltration.

We observed in this RCT that MSI changed to a stable status or newly developed methylation to some degree in the non-eradicated group, and that MSI occurred or epigenetic alterations changed from unmethylated to methylated status in some cases in the eradication group - a phenomenon that is difficult to explain. One possibility is that MSI and gene methylation events are not always uniformly distributed throughout the stomach (Perri et al, 2007). Indeed, the biopsy specimens evaluated here in the RCT may not coincide completely between the baseline and at 1-year follow-up, and thus the possibility of sampling error cannot be ruled out. In addition, a certain condition, that is, the extension of IM with molecular events, is consistent with the hypothesis of field cancerisation of the stomach, and thus $H$. pylori therapy may not be able to reverse the course of gastric carcinogenesis (Zaky et al, 2008).

Individuals with residual methylation after $H$. pylori eradication may have a risk of gastric cancer development. Wong et al (2004) reported that they observed no overall reduction of cancer development by $H$. pylori treatment in their patient subgroup with precancerous lesions, that is, atrophic gastritis or IM. Thus, they emphasised the concept of a 'point of no return' (Wong et al, 2004; Wright and Kelly, 2006) in which the benefits of H. pylori eradication diminish after the IM stage reaches a point at which molecular changes are irreversible. Our present findings may support their conclusion, which is that once gastric cancer has developed in the background mucosa with IM, H. pylori treatment may not be helpful to change the course.

The present study has the following three limitations. First, this was a study from a single institution with a small number of patients who underwent ESD. Second, the number of cases analysed in the RCT was small, particularly considering that several different molecular markers and cellular phenotypes were compared. In the number of cases evaluated (19 cases in the eradicated group and 17 cases in the non-eradicated group), the improved incidences of MSI were $73.7 \%$ in the eradication group vs $58.8 \%$ in the non-eradicated group, which were different from the improved incidences that were a priori assumed to calculate the sample size in Study 2, that is, $70 \%$ vs $15 \%$, respectively. In fact, the statistical power that detects a difference in the improved incidence of stable MSI after the intervention was $10 \%$ at the significance level of $\alpha=0.05$ (two-sided) by Fisher's exact test. This lack of power may thus have affected the present results in which a significant change of MSI (the primary end point) by the intervention was not identified, thus indicating that our findings in the RCT might be underestimated. Also, the statistical power of sample size may be somewhat weak $(\sim 60 \%)$ in Study 1 . However, the incidence of all molecular alterations did not show significant differences between the $H$. pylori-positive and -negative patients who underwent ESD for gastric neoplasia (Study 1), and this result may thus compensate for the lack of statistical power in the RCT (Study 2). Nevertheless, we believe that the data presented in the present study are of value, and that they will generate further efforts among researchers to extend these studies. Third, as the intervention period of the RCT was short, it may be necessary to conduct follow-ups for a long time, for example, more than 1 year. Choi et al (2014) postulated that a long-term investigation (over 5 years) could clarify the exact role of $H$. pylori eradication. Changes in a cellular phenotype (as identified by mAb Das- 1 reactivity) by $H$. pylori treatment require substantial time, as we mentioned (Watari et al, 2012).

In conclusion, we found that (1) MSI and mAb Das-1 reactivity in IM are markers of the risk of cancer development; (2) there were no significant differences in MSI or other molecular events in IM between $H$. pylori-positive and -negative patients who underwent ER; and (3) an RCT did not show significant molecular changes in IM between the eradicated and non-eradicated groups. These results indicate that the cure of $H$. pylori may not prevent MGC in the background mucosa with IM.

\section{CONFLICT OF INTEREST}

This study was supported by a grant-in-aid for Researchers, Hyogo College of Medicine, 2011 and a research grant (National Institute of Diabetes and Digestive and Kidney Disease, RO1DK63618 to KMD) from the National Institutes of Health (Bethesda, MD, USA).

\section{REFERENCES}

Avraham A, Uhlmann R, Shperber A, Birnbaum M, Sandbank J, Sella A, Sukumar S, Evron E (2012) Serum DNA methylation for monitoring response to neoadjuvant chemotherapy in breast cancer patients. Int $J$ Cancer 131: E1166-E1172.

Bae SE, Jung HY, Kang J, Park YS, Baek S, Jung JH, Choi JY, Kim MY, Ahn JY, Choi KS, Kim do H, Lee JH, Choi KD, Song HJ, Lee GH, Kim JH (2014) Effect of Helicobacter pylori eradication on metachronous recurrence after endoscopic resection of gastric neoplasm. Am J Gastroenterol 109: 60-67.

Balic M, Pichler M, Strutz J, Heitzer E, Ausch C, Samonigg H, Cote RJ, Dandachi N (2009) High quality assessment of DNA methylation in archival tissues from colorectal cancer patients using quantitative highresolution melting analysis. J Mol Diagn 11: 102-108.

Buonsanti G, Calistri D, Padovan L, Luinetti O, Fiocca R, Solcia E, Ranzani GN (1997) Microsatellite instability in intestinal and diffuse-type gastric carcinoma. J Pathol 182: 167-173.

Chan AO, Lam SK, Wong BC, Wong WM, Yuen MF, Yeung YH, Hui WM, Rashid A, Kwong YL (2003) Promoter methylation of E-cadherin gene in gastric mucosa associated with Helicobacter pylori infection and in gastric cancer. Gut 52: 502-506. 
Chan AO, Peng JZ, Lam SK, Lai KC, Yuen MF, Cheung HK, Kwong YL, Rashid A, Chan CK, Wong BC (2006) Eradication of Helicobacter pylori infection reverses E-cadherin promoter hypermethylation. Gut 55: 463-468.

Choi J, Kim SG, Yoon H, Im JP, Kim JS, Kim WH, Jung HC (2014) Eradication of Helicobacter pylori after endoscopic resection of gastric tumors does not reduce incidence of metachronous gastric carcinoma. Clin Gastroenterol Hepatol 12: 793-800.e1.

Chung YJ, Song JM, Lee JY, Jung YT, Seo EJ, Choi SW, Rhyu MG (1996) Microsatellite instability-associated mutations associate preferentially with the intestinal type of primary gastric carcinomas in a high-risk population. Cancer Res 56: 4662-4665.

Correa P (1988) A human model of gastric carcinogenesis. Cancer Res 48: 3554-3560.

Correa P, Fox J, Fontham E, Ruiz B, Lin Y, Zavala D, Taylor N, Mackinley D, De Lima E, Portilla H, Zarama G (1990) Helicobacter pylori and gastric carcinoma. Serum antibody prevalence in populations with contrasting cancer risks. Cancer 66: 2569-2574.

Das KM, Sakamaki S, Vecchi M, Diamond B (1987) The production and characterization of monoclonal antibodies to a human colonic antigen associated with ulcerative colitis: cellular localization of the antigen by using the monoclonal antibody. J Immunol 139: 77-84.

Dong CX, Deng DJ, Pan KF, Zhang L, Zhang Y, Zhou J, You WC (2009) Promoter methylation of p16 associated with Helicobacter pylori infection in precancerous gastric lesions: a population-based study. Int J Cancer 124: 434-439.

Ferlay J, Shin HR, Bray F, Forman D, Mathers C, Parkin DM (2010) Estimates of worldwide burden of cancer in 2008: GLOBOCAN 2008. Int J Cancer 127: 2893-2917.

Filipe MI, Munoz N, Matko I, Kato I, Pompe-Kirn V, Jutersek A, Teuchmann S, Benz M, Prijon T (1994) Intestinal metaplasia types and the risk of gastric cancer: a cohort study in Slovenia. Int J Cancer 57: 324-329.

Fuccio L, Zagari RM, Eusebi LH, Laterza L, Cennamo V, Ceroni L, Grilli D, Bazzoli F (2009) Meta-analysis: can Helicobacter pylori eradication treatment reduce the risk for gastric cancer? Ann Intern Med 151: 121-128.

Fukase K, Kato M, Kikuchi S, Inoue K, Uemura N, Okamoto S, Terao S, Amagai K, Hayashi S, Asaka M. Japan Gast Study Group (2008) Effect of eradication of Helicobacter pylori on incidence of metachronous gastric carcinoma after endoscopic resection of early gastric cancer: an open-label, randamised controlled trial. Lancet 372: 392-397.

Gologan A, Graham DY, Sepulveda AR (2005) Molecular markers in Helicobacter pylori-associated gastric carcinogenesis. Clin Lab Med 25: $197-222$.

International Agency for Research on Cancer (1994) IARC Monographs on the Evaluation of Carcinogenic Risks TO Humans. Schistosomes, Liver Flukes and Helicobacter pylori volume 61IARC: Lyon, France, pp 177-240.

Japanese Gastric Cancer Association (2011) Japanese Classification of Gastric Carcinoma - 3rd English edition. Gastric Cancer 14: 101-112.

Jung S, Park CH, Kim EH, Shin SJ, Chung H, Lee H, Park JC, Shin SK, Lee YC Lee SK (2015) Preventing metachronous gastric lesions after endoscopic submucosal dissection through Helicobacter pylori eradication. J Gastroenterol Hepatol 30: 75-81.

Kang GH, Lee HJ, Hwang KS, Lee S, Kim JH, Kim JS (2003) Aberrant CpG island hypermethylation of chronic gastritis, in relation to aging, gender, intestinal metaplasia, and chronic inflammation. Am J Pathol 163: 1551-1556.

Kang GH, Lee S, Cho NY, Gandamihardja T, Long TI, Weisenberger DJ, Campan M, Laird PW (2008) DNA methylation profiles of gastric carcinoma characterized by quantitative DNA methylation analysis. Lab Invest 88: 161-170.

Kato M, Nishida T, Yamamoto K, Hayashi S, Kitamura S, Yabuta T, Yoshio T, Nakamura T, Komori M, Kawai N, Nishihara A, Nakanishi F, Nakahara M, Ogiyama H, Kinoshita K, Yamada T, Iijima H, Tsujii M, Takehara T (2013) Scheduled endoscopic surveillance controls secondary cancer after curative endoscopic resection for early gastric cancer: a multicentre retrospective cohort study by Osaka University ESD study group. Gut 62: 1425-1432.

Kimura K, Takemoto T (1969) An endoscopic recognition of the atrophic border and its significance in chronic gastritis. Endoscopy 3: 87-97.

Kristensen LS, Hansen LL (2009) PCR-based methods for detecting singlelocus DNA methylation biomarkers in cancer diagnostics, prognostics, and response to treatment. Clin Chem 55: 1471-1483.

Leung WK, Man EP, Yu J, Go MY, To KF, Yamaoka Y, Cheng VY, Ng EK, Sung JJ (2006) Effects of Helicobacter pylori eradication on methylation status of E-cadherin gene in noncancerous stomach. Clin Cancer Res 12: 3216-3221.

Li WQ, Pan KF, Zhang Y, Dong CX, Zhang L, Ma JL, Zhou T, Li JY, You WC (2011) RUNX3 methylation and expression associated with advanced precancerous gastric lesions in a Chinese population. Carcinogenesis 32: 406-410.

Maehata Y, Nakamura S, Fujisawa K, Esaki M, Moriyama T, Asano K, Fuyuno Y, Yamaguchi K, Egashira I, Kim H, Kanda M, Hirahashi M, Matsumoto T (2012) Long-term effect of Helicobacter pylori eradication on the development of metachronous gastric cancer after endoscopic resection of early gastric cancer. Gastrointest Endosc 75: 39-46.

Maekita T, Nakazawa K, Mihara M, Nakajima T, Yanaoka K, Iguchi M, Arii K, Kaneda A, Tsukamoto T, Tatematsu M, Tamura G, Saito D, Sugimura T, Ichinose M, Ushijima T (2006) High levels of aberrant DNA methylation in Helicobacter pylori-infected gastric mucosae and its possible association with gastric cancer risk. Clin Cancer Res 12: 989-995.

Dinis-Ribeiro M, Areia M, de Vries AC, Marcos-Pinto R, Monteiro-Soares M, O'Connor A, Pereira C, Pimentel-Nunes P, Correia R, Ensari A, Dumonceau JM, Machado JC, Macedo G, Malfertheiner P, MatysiakBudnik T, Megraud F, Miki K, O’Morain C, Peek RM, Ponchon T, Ristimaki A, Rembacken B, Carneiro F, Kuipers EJ. European Society of Gastrointestinal Endoscopy; European Helicobacter Study Group; European Society of Pathology; Sociedade Portuguesa de Endoscopia Digestiva. Management of precancerous conditions and lesions in the stomach (MAPS): guideline from the European Society of Gastrointestinal Endoscopy (ESGE), European Helicobacter Study Group (EHSG), European Society of Pathology (ESP), and the Sociedade Portuguesa de Endoscopia Digestiva (SPED) (2012) Endoscopy 44: 74-94.

Marrano D, Viti G, Grigioni W, Marra A (1987) Synchronous and metachronous cancer of the stomach. Eur J Surg Oncol 13: 493-498.

Meng W, Huebner A, Shabsigh A, Chakravarti A, Lautenschlaeger T (2012) Combined RASSF1A and RASSF2A promoter methylation analysis as diagnostic biomarker for bladder cancer. Mol Biol Int 2012: 701814.

Mirza ZK, Das KK, Slate J, Mapitigama RN, Amenta PS, Griffel LH, Ramsundar L, Watari J, Yokota K, Tanabe H, Sato T, Kohgo Y, Das KM (2003) Gastric intestinal metaplasia as detected by a novel biomarker is highly associated with gastric adenocarcinoma. Gut 52: 807-812.

Morandi L, Franceschi E, de Biase D, Marucci G, Tosoni A, Ermani M, Pession A, Tallini G, Brandes A (2010) Promoter methylation analysis of O6-methylguanine-DNA methyltransferase in glioblastoma: detection by locked nucleic acid based quantitative PCR using an imprinted gene (SNURF) as a reference. BMC Cancer 10: 48.

Nakajima T, Enomoto S, Yamashita S, Ando T, Nakanishi Y, Nakazawa K, Oda I, Gotoda T, Ushijima T (2010) Persistence of a component of DNA methylation in gastric mucosae after Helicobacter pylori eradication. J Gastroenterol 45: 37-44.

Pang JM, Deb S, Takano EA, Byrne DJ, Jene N, Boulghourjian A, Holliday A, Millar E, Lee CS, O’Toole SA, Dobrovic A, Fox SB (2014) Methylation profiling of ductal carcinoma in situ and its relationship to histopathological features. Breast Cancer Res 16: 423.

Park SY, Yoo EJ, Cho NY, Kim N, Kang GH (2009) Comparison of CpG island hypermethylation and repetitive DNA hypomethylation in premalignant stages of gastric cancer, stratified for Helicobacter pylori infection. J Pathol 219: 410-416.

Perri F, Cotugno R, Piepoli A, Merla A, Quitadamo M, Gentile A, Pilotto A, Annese V, Andriulli A (2007) Aberrant DNA methylation in nonneoplastic gastric mucosa of $H$. pylori infected patients and effect of eradication. Am J Gastroenterol 102: 1361-1371.

Schlemper RJ, Riddell RH, Kato Y, Borchard F, Cooper HS, Dawsey SM, Dixon MF, Fenoglio-Preiser CM, Fléjou JF, Geboes K, Hattori T, Hirota T, Itabashi M, Iwafuchi M, Iwashita A, Kim YI, Kirchner T, Klimpfinger M, Koike M, Lauwers GY, Lewin KJ, Oberhuber G, Offner F, Price AB, Rubio CA, Shimizu M, Shimoda T, Sipponen P, Solcia E, Stolte M, Watanabe H, Yamabe H (2000) The Vienna classification of gastrointestinal epithelial neoplasia. Gut 47: 251-255.

Sepulveda AR, Yao Y, Yan W, Park DI, Kim JJ, Gooding W, Abudayyeh S, Graham DY (2010) CpG methylation and reduced expression of O6methylguanine DNA methyltransferase is associated with Helicobacter pylori infection. Gastroenterology 138: 1836-1844.

Shin CM, Kim N, Lee HS, Park JH, Ahn S, Kang GH, Kim JM, Kim JS, Lee DH, Jung HC (2013) Changes in aberrant DNA methylation after Helicobacter pylori eradication: a long-term follow-up study. Int J Cancer 133: 2034-2042. 
Sipponen P, Hyvärinen H. Role of Helicobacter pylori in the pathogenesis of gastritis, peptic ulcer and gastric cancer (1993) Scand J Gastroenterol 196(Suppl): 3-6.

Sugai T, Habano W, Jiao YF, Toyota M, Suzuki H, Tsukahara M, Koizuka H, Akasaka R, Koeda K, Wakabayashi G, Suzuki K (2010) Molecular analysis of single isolated glands in gastric cancers and their surrounding gastric intestinal metaplastic mucosa. Oncol Rep 23: 25-33.

Tahara T, Shibata T, Nakamura M, Yamashita H, Yoshioka D, Okubo M, Yonemura J, Maeda Y, Maruyama N, Kamano T, Kamiya Y, Fujita H, Nakagawa Y, Nagasaka M, Iwata M, Hirata I, Arisawa T (2010) Increased number of $\mathrm{CpG}$ island hypermethylation in tumor suppressor genes of non-neoplastic gastric mucosa correlates with higher risk of gastric cancer. Digestion 82: 27-36.

Take S, Mizuno M, Ishiki K, Yoshida T, Ohara N, Yokota K, Oguma K, Okada H, Yamamoto K (2011) The long-term risk of gastric cancer after the successful eradication of Helicobacter pylori. J Gastroenterol 46: 318-324.

Tanaka A, Watari J, Tanabe H, Maemoto A, Fujiya M, Ashida T, Das KM, Kohgo Y (2006) Effect of eradication of Helicobacter pylori on genetic instabilities in gastric intestinal metaplasia. Aliment Pharmacol Ther 24(Suppl 4): 194-202.

To KF, Leung WK, Lee TL, Tong JH, Chan MW, Ng EK, Chung SC, Sung JJ (2002) Promoter hypermethylation of tumor-related genes in gastric intestinal metaplasia of patients with and without gastric cancer. Int $J$ Cancer 102: 623-628.

Toyota M, Ahuja N, Suzuki H, Itoh F, Ohe-Toyota M, Imai K, Baylin SB, Issa JP (1999) Aberrant methylation in gastric cancer associated with the CpG island methylator phenotype. Cancer Res 59: 5438-5442.

Uemura N, Mukai T, Okamoto S, Yamaguchi S, Mashiba H, Taniyama K, Sasaki N, Haruma K, Sumii K, Kajiyama G (1997) Effect of Helicobacter pylori eradication on subsequent development of cancer after endoscopic resection of early gastric cancer. Cancer Epidemiol Biomarkers Prev 6: 639-642.

Uemura N, Okamoto S, Yamamoto S, Matsumura N, Yamaguchi S, Yamakido M, Taniyama K, Sasaki N, Schlemper RJ (2001) Helicobacter pylori infection and the development of gastric cancer. N Engl J Med 345: 784-789.

Umar A, Boland CR, Terdiman JP, Syngal S, de la Chapelle A, Rüschoff J, Fishel R, Lindor NM, Burgart LJ, Hamelin R, Hamilton SR, Hiatt RA,
Jass J, Lindblom A, Lynch HT, Peltomaki P, Ramsey SD, Rodriguez-Bigas MA, Vasen HF, Hawk ET, Barrett JC, Freedman AN, Srivastava S (2004) Revised Bethesda Guidelines for hereditary nonpolyposis colorectal cancer (Lynch syndrome) and microsatellite instability. J Natl Cancer Inst 96: 261-268.

Watari J, Das KK, Amenta PS, Tanabe H, Tanaka A, Geng X, Lin JJ, Kohgo Y, Das KM (2008) Effect of eradication of Helicobacter pylori on the histology and cellular phenotype of gastric intestinal metaplasia. Clin Gastroenterol Hepatol 6: 409-417.

Watari J, Moriichi K, Tanabe H, Kashima S, Nomura Y, Fujiya M, Tomita T, Oshima T, Fukui H, Miwa H, Das KM, Kohgo Y (2012) Biomarkers predicting development of metachronous gastric cancer after endoscopic resection: an analysis of molecular pathology of Helicobacter pylori eradication. Int J Cancer 130: 2349-2358.

Wojdacz TK, Dobrovic A (2007) Methylation-sensitive high resolution melting (MS-HRM): a new approach for sensitive and high-throughput assessment of methylation. Nucleic Acids Res 35: e41.

Wong BC, Lam SK, Wong WM, Chen JS, Zheng TT, Feng RE, Lai KC, Hu WH, Yuen ST, Leung SY, Fong DY, Ho J, Ching CK, Chen JS. China Gastric Cancer Study Group (2004) Helicobacter pylori eradication to prevent gastric cancer in a high-risk region of China: a randomized controlled trial. JAMA 291: 187-194.

Wright CL, Kelly JK (2006) The use of routine special stains for upper gastrointestinal biopsies. Am J Surg Pathol 30: 357-361.

Yoon SB, Park JM, Lim CH, Cho YK, Choi MG (2014) Effect of Helicobacter pylori eradication on metachronous gastric cancer after endoscopic resection of gastric tumors: a meta-analysis. Helicobacter 19: 243-248.

Zaky A, Watari J, Tanabe H, Sato R, Moriichi K, Tanaka A, Maemoto A, Fujiya M, Ashida T, Kohgo Y (2008) Clinicopathological implications of genetic instability in intestinal type gastric cancer and intestinal metaplasia as a precancerous lesion: proof of field cancerization in the stomach. Am J Clin Pathol 129: 613-621.

This work is published under the standard license to publish agreement. After 12 months the work will become freely available and the license terms will switch to a Creative Commons AttributionNonCommercial-Share Alike 4.0 Unported License.

Supplementary Information accompanies this paper on British Journal of Cancer website (http://www.nature.com/bjc) 